\title{
EVALUATION OF THE EFFICACY OF AMNIOTIC CHORION MEMBRANE IN MANAGEMENT OF GRADE II FURCATION DEFECTS (CLINICAL STUDY)
}

\author{
Raneem M. Gamal ${ }^{1} B D S$, Mona Lotfy² $P H D$, Maha Taalab ${ }^{3} P H D$
}

\begin{abstract}
INTRODUCTION: Treatment of molar furcation defects remains a considerable challenge in clinical practice. Furcation defects treatment can vary according to the type and location of the defects. Regenerative procedures are one of the treatment modalities in furcation involvement. In this study Amnion Chorion membrane(ACM) was used with an alloplast to manage grade II furcation defects.

OBJECTIVES The aim of this study was to evaluate clinically and radiographically the effect of ACM augmented with alloplast bone graft in management of grade II furcation involvement.

MATERIALS AND METHODS: This study was conducted clinically on fourteen patients with fourteen grade II furcation defects. Patients were divided into two groups: test group: included seven furcation defects that were treated by alloplast bone graft covered by ACM, and control group: including seven furcation defects treated with alloplast bone graft covered by a resorbable collagen membrane. Probing depth (P D), clinical attachment loss(CAL)were measured at baseline,3, and 6 months. Cone beam computed tomography(CBCT)was performed at baseline,6, and9months to evaluate bonefill in the furcation defect.

RESULTS: ACM has shown reduction in probing depth and clinical attachment loss, and enhanced bone formation when compared to control group treated with resorbable collagen membrane.

CONCLUSIONS: ACM is an effective, easy to handle, safe, and time saving membrane that can be used in periodontal regeneration. KEYWORDS: Amniotic chorion membrane- Grade II furcation defects

1- BDS, Faculty of Dentistry, Alexandria University, Alexandria, Egypt.

2- Professor of Oral Medicine, Periodontology, Oral Diagnosis and Radiology Department, Faculty of Dentistry, Alexandria University, Alexandria, Egypt.

3- Lecturer of Oral Medicine, Periodontology, Oral Diagnosis and Radiology Department, Faculty of Dentistry, Alexandria University, Alexandria, Egypt.

Corresponding author:

E-mail: raneemgamal00@hotmail.com
\end{abstract}

\section{INTRODUCTION}

Periodontal disease is an inflammatory condition that occurs as a result of specific microorganism or groups of specific microorganisms, resulting in progressive destruction of the periodontium (1). Uncontrolled progression of inflammatory periodontal disease ultimately results in attachment loss sufficient enough to affect bifurcation or trifurcation of multi rooted teeth (2). Bacterial plaque and the inflammatory consequences resulting from its long term presence represent the primary etiologic factor in the development of furcation defects. Dental caries and pulpal involvement (2), chronic trauma from occlusion (3), and iatrogenic factors such as; over hanging restorations can also lead to furcation involvement (4).

Debridement of furcation area by routine periodontal instrumentation is very difficult due to its complex anatomic morphology. Therefore, furcation involvement in molars represents one of the major challenges to manage in clinical periodontics (5).

Attempts to treat furcation lesions have led to therapies ranging from nonsurgical periodontal therapy, such as scaling and root planing (SRP), to surgical root debridement, root resection, hemisection, regenerative therapy, and attempts in tissue engineering (6). Generally, advanced grade II furcation involvement in mandibular molars and buccal furcations in maxillary molars can be successfully treated by regenerative procedures (7).

The ultimate goal of the regenerative procedures is to exclude the epithelium and the gingival corium from the root to delay epithelial down growth during healing and to provide an opportunity for progenitor cells of the periodontal ligament and bone to repopulate previously diseased root surfaces using guided tissue regeneration materials (GTR) (8).

Clinical studies have shown that guided tissue regeneration (GTR) can improve the response of advanced grade II furcation defects to therapy by means of pocket reduction, gain in clinical attachment levels and bone defect fill. The improvement in these clinical parameters plus the potential of creating new attachment leads to the consideration of GTR approach as the treatment of choice in furcation defects (9). Among the regenerative procedures which have been used for treating grade II furcation involvement was the use of a composite bone substitute graft combined with a non-absorbable or bio absorbable barrier membranes and a coronally positioned flap (10). Other modalities as osteogenic protein -1 (OP-1) which is a member of the transforming growth factor beta super family and enamel matrix derivative have also been used (11). Recently, amniotic chorion membrane (ACM) which contains a multitude of growth factors has been used (12).

Amniotic chorion membrane (ACM) which is a placental based membrane, is composed of amniotic membrane(AM), and chorion membrane. AM represents the innermost layer of the placenta, is composed of a single epithelial layer, thick basement membrane and avascular stroma. While chorion tissue which forms the outer limits of the sac is composed of a reticular layer, basement membrane, and trophoblasts (13). Unlike other barrier membranes, ACM is biologically active due to the presence of bioactive proteins and growth factors (GF) 
that hasten granulation tissue formation and act as a bioactive matrix that facilitates cell migration.Wound healing property is further enhanced by the physiological seal obtained with the gingiva (12).

Immunohistochemical (IHC) staining of amniotic chorion membrane shows intense concentrations of laminin and laminin-5 in the barrier. Laminin-5 has affinity for binding gingival epithelial cells $(13,14)$. ACM provides a protein enriched matrix which naturally hastens cellular migration across the exposed portion of the barrier. These unique biological properties allow ACM to be left exposed to the oral environment (12).

ACM is used for tissue engineering in the reconstruction of occular surface, management of Steven Johnsons syndrome, chemical burns, nerve regeneration, skin reconstruction, endothelial cell cultivation, local drug delivery, and as a GTR membrane in treatment of periodontal osseous defects, gingival recessions, and furcation defects (12).

In spite of the membrane's safety, few studies have been conducted to evaluate GTR procedures using ACM augmented with bone graft in the management of furcation defects.

\section{MATERIALS AND METHODS}

\section{i. Study design}

The study design was a simple random sample technique (clinical trial) that was conducted on fourteen patients having fourteen grade II furcation defects in the lower molars attending the clinic of the Periodontology and Oral Medicine Department, Faculty of Dentistry, Alexandria University (15).

The research protocol was approved by the Ethical Committee of the Faculty of dentistry Alexandria University, and an informed consent was obtained from each patient after providing detailed information and description of the study.

\section{ii. Sample Size}

A sample of 14 patients; 7 per group with critical size grade II furcation defects was required to estimate an average success (bone filling) for $\mathrm{ACM}=66.7 \%$, using alpha error $=0.05$ and precision $=10 \%$ provided a study power of $80 \%$. $(16,17)$

The sample size was calculated using G.power software.

iii. Criteria for patient selection Inclusion Criteria

- Presence of a lower posterior tooth with critical size grade II furcation defect (15) with a horizontal component of 4 $\mathrm{mm}$ and a vertical component of 4 to $6 \mathrm{~mm}$ (18), detected using Naber's probe (Nordent,NewYork,USA) and a William's calibrated periodontal probe (Nordent,NewYork,USA).

- Patient's age between 25 - 50 years.

- Both sexes.

- Patients psychologically accepting the procedures.

- Patients systemically free.

\section{Exclusion criteria}

- Uncooperative patients regarding oral hygiene measures performance.

- Patients with para functional habits.

- Smokers.

- Pregnant or lactating women.
- Patients that had been submitted to any periodontal surgeries in the previous six months.

- Patients that had received medication in the previous six months.

- Patients were divided randomly into two groups:

- Group I (Test group): In which seven grade-2 furcation defects were managed with alloplast bone graft covered by amniotic chorion membrane.

- Group II (Control group): In which seven grade-2 furcation defects were managed with alloplast bone graft covered by resorbable collagen membrane.

\section{Materials}

1. Amnion Chorion Membrane (ACM) (10x25mm) allograft, (Bioxclude) (Snoasis Medical, Denver,USA).

2. Resorbable collagen membrane (15x20x0.3 mm) (T-Gen) (Bioland, Songjeongri,South Korea).

3. Bone alloplast (biphasic calcium phosphate $(\mathrm{BCP}))=$ beta tri calcium phosphate + hydroxy apatite, (500-1000 $\mu \mathrm{m}$ 1g) (Genesis) ( Dio Implant,Busan,South Korea).

\section{Methods}

A) Pre surgical phase

The following clinical and radiographic examinations were performed on all patients:

1. Probing depth (PD) (19).

2. Clinical attachment loss (CAL) (18).

All these clinical measurements were performed at baseline, three months, and six months.

\section{Radiographic examination}

1. Orthopantomogram (OPG) was done at the first visit for selection of patients.

2. Cone beam computed tomography (C.B.C.T) was performed using the high-resolution imaging system 3D J. Morita, to indicate level of alveolar bone at the furcation area.

3. The slice thickness was set at $0.5 \mathrm{~mm}$, and the pitch was set at $0.125 \mathrm{~mm}$.

4. Measurements were done to the nearest $0.5 \mathrm{~mm}$ using the On Demand 3D software by Cybermed Inc. with a linear measurement tool and a digital magnification lens (20).

5. Furcation involvement was calculated in the horizontal plane by measuring, to the nearest 0.5 millimeter the distance between the outer root surface and the interradicular bone (bone loss in the horizontal direction - 'BLH'). The degree of FI was graded according to Glickman's (15) classification system. (Figure 1)

6. Degree of bone loss in the vertical direction (BL-V) was calculated by measuring the distance from the furcation entrance to the base of the defect in the vertical direction (18). (Figure 1)
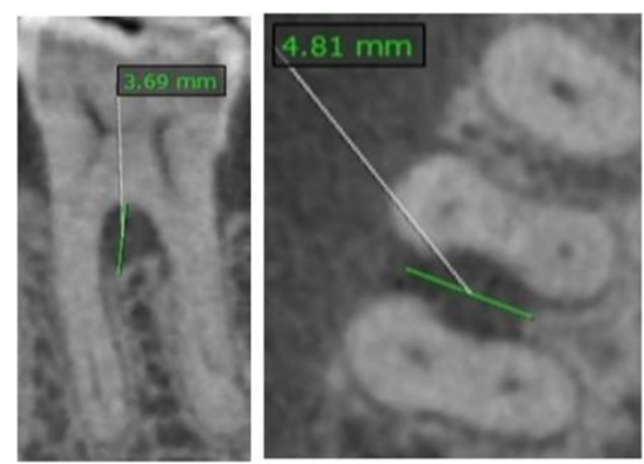

Figure 1: CBCT image showing vertical component (Left) and horizontal component (Right) of the furcation defect in lower right 1st molar at baseline. 
7. Radiographic examination using cone beam computed tomography (C.B.C.T) was performed at baseline, six, and nine months.

\section{Phase 1 therapy}

1. Oral hygiene instructions were given to patients.

2. Scaling and root planing.

3. Coronoplasty was done when needed.

B) Surgical phase (Figure2\&3)

1. All patients were operated under local anesthesia using Mepicaine-L (Alexandria company for pharmaceuticals and chemical industries, Alexandria,Egypt)with nerve block technique in the surgical field.

2. Gingival sulcular incision was done using 15C blade extending one tooth mesial and one tooth distal to the selected tooth.

3. Full thickness mucoperiosteal flap was reflected using a periosteal elevator (Kohler,Southern Germany).

4. Degranulation of the surgical field was done using CK6 surgical scaler (Kohler,Southern Germany) and 4R-4L Colombia curettes (Kohler,Southern Germany).

5. The size of the defect was measured horizontally and vertically using Naber's probe (Nordent,NewYork,USA) and William's calibrated periodontal probe (Nordent,NewYork,USA) respectively.

6. Bone graft was mixed with the patient's own blood in a sterile dapen dish and applied in the furcation defect using bone curette (Kohler,Southern Germany).

7. Membrane application:

Group I (Test group)

- ACM was applied over the alloplast in the defect according to its size. It extended from the CEJ occlusoapically by one mm below the furcation level and two mm beyond the furcation area mesiodistally.

- ACM was adapted over the defect using a damp piece of gauze which was pressed on it for few minutes to ensure proper adherence.

\section{Group II (Control group)}

- Resorbable collagen membrane was trimmed according to the size of the defect.

- Resorbable collagen membrane was applied over the alloplast bone graft in the defect extending from the CEJ occlusoapically one mm below the furcation level and two $\mathrm{mm}$ beyond the furcation area mesiodistally.

- Resorbable collagen membrane was adapted and secured in place over the defect using 4-0 polyglycolic acid(Surgicryl,Steinerberg,Belgium) resorbable suture.

- Flap was then repositioned using non-resorbable 4-0 polypropylene (Unipro,Unimed,Kingdom Of Saudi Arabia) interrupted sutures.
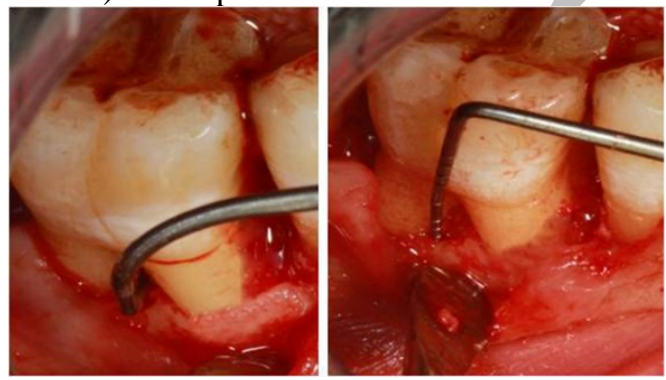

Figure 2: Mucoperiosteal flap reflection and a) measurement of the horizontal component of the furcation defect (Left) b) measurement of the vertical component of the furcation defect (Right).
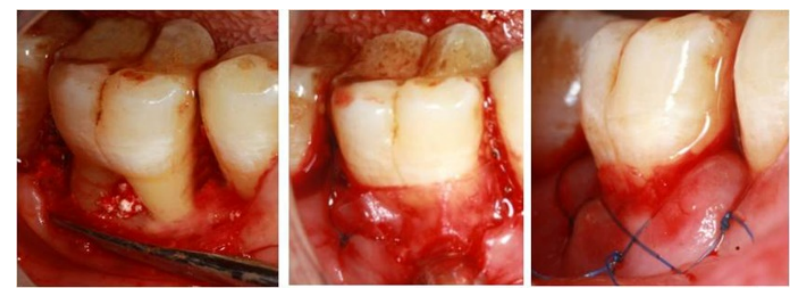

Figure 3: a) Bone graft application in the defect (Left), b)application of the amniotic chorion membrane (Middle), c) flap repositioning and suturing ${ }^{\text {(Right). }}$

\section{C) Post surgical phase}

- Postoperative medications including Amoxicillin clavulanate $\quad 1 \mathrm{gm}$ (Augmentin,Galaxo Smith Kline,Brentford,United kingdom); 1 capsule every 12 hours for 5 days and non-steroidal anti-inflammatory drug: ibuprofen (BRUFEN,Abbotl,Chicago,USA) $1800 \mathrm{mg}, 1$ tablet 3 times daily after meals for 4 days were prescribed.

- Sutures were removed ten days post surgically.

Statistical analysis of the data (21)

Data were fed to a computer and analyzed using IBM SPSS software package version 20.0. (22) Qualitative data were described using number and percent. The Kolmogorov-Smirnov test was used to verify the normality of distribution Quantitative data were described using range (minimum and maximum), mean, standard deviation and median. Significance of the obtained results was judged at the $5 \%$ level using Student t-test, Mann Whitney test, Wilcoxon signed ranks test, and Friedman test.

\section{RESULTS}

\section{Clinical results (Figure 4)}

\section{Pain, tenderness, infection or swelling}

There was absence of pain and tenderness on the first postsurgical days and during the follow up period. Post operative edema and discomfort were very minimal and unobserved. Healing was uneventful in all cases with no postoperative swelling or infection.
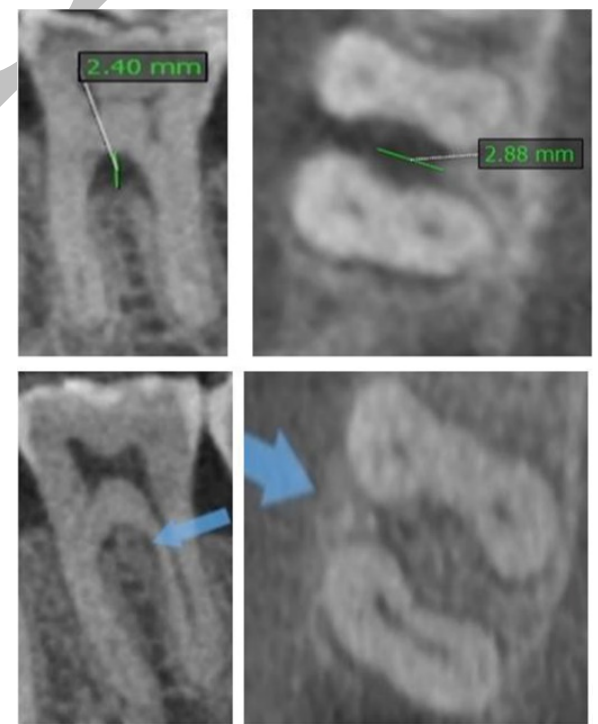

Figure 4: CBCT image showing a) vertical component ( 'BL-V :2.40 2.00) (Upper Left) and horizontal component ('BL$\mathrm{H}: 2.88 \sim 3.00$ ) (Upper Right) of the furcation defect in lower right 1st molar after 6 months, b)vertical component ( 'BL-V :0) (Lower Left) and horizontal component ('BL-H:0) (Lower Right) of the furcation defect in lower right 1 st molar after 9 months. 


\section{Probing depth (PD) in mm:(Figure 5)}

At baseline, for test group the mean of PD was (3.71 \pm $0.76 \mathrm{~mm})$, while for control group it was $(3.71 \pm 0.95 \mathrm{~mm})$.

In test group, there was a significant reduction in PD when comparing baseline values to those post-operatively (Pbase:0.008*,0.018*). However, no significant difference was found when comparing between the follow up periods. (P1:0.172)

As for control group, no significant difference was present neither when comparing baseline to 3 and 6 months (Pbase:0.356, 0.356), nor when comparing between the follow up periods in control group. (P1:0.356)

On comparing both groups, there was a reduction of PD of test group throughout the follow up period more than control group, yet the difference was not significant (P: 0.730,0.290) (T: 0.354,1.108) respectively.

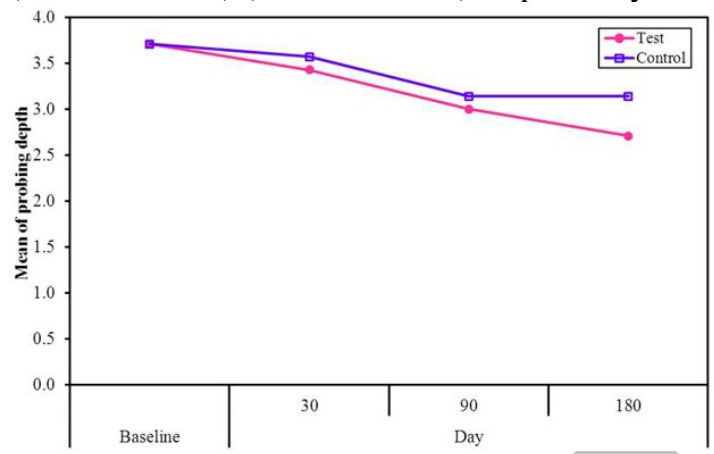

Figure 5: Comparison between the two studied groups with respect to probing depth (in $\mathrm{mm}$ ).

\section{Clinical attachment loss (CAL)in mm: (Figure 6)}

At baseline, for test group the mean of CAL was (3.57 \pm $0.53 \mathrm{~mm})$, while for control group it was $(3.57 \pm 0.98 \mathrm{~mm})$. Although there was reduction of CAL throughout the follow up period in test group, yet no significant difference was noted neither when comparing baseline to 3,and 6 months in both groups(Pbase: 0.059,0.059for test group) and (Pbase: 0.458,0.458 for control group ), nor when comparing between the follow up periods in both groups (P 1 :0.083 for test group) and (P1 :1.000 for control group).

On comparing between both groups, no significant difference was noted at 3 months (P: 0.091) (U: 15.00), while a significant difference was realized after 6 months for test group compared to control group. (P:0.015*) (U: 7.500*)

A statistically significant reduction of CAL in test group was present by the end of the follow up period compared to control group.

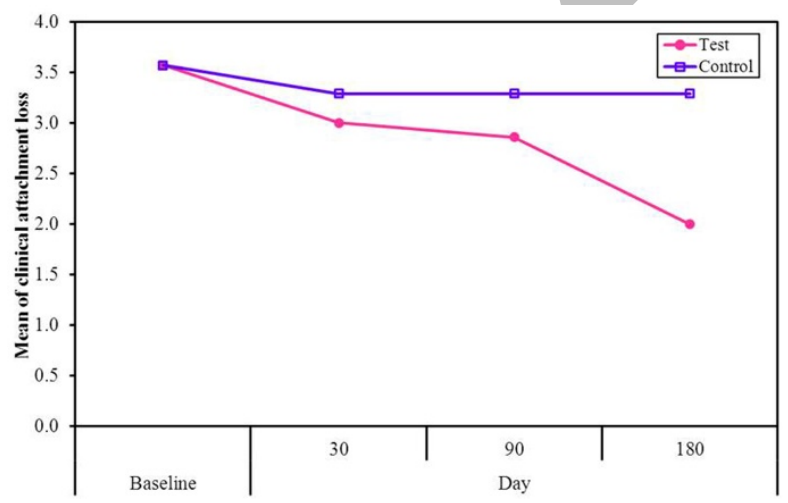

Figure 6:Comparison between the two studied groups with respect to clinical attachment loss (in $\mathrm{mm}$ ).

\section{Radiographic results}

\section{Horizontal component of the Furcation in $\mathrm{mm}$ :(Table} 1)

At baseline, for test group the mean of horizontal component of the furcation was $(4.64 \pm 0.48 \mathrm{~mm})$, while for control group it was $(4.57 \pm 0.45 \mathrm{~mm})$.

A significant reduction of the horizontal component of the furcation was noted in test group when comparing baseline to 6 and 9 months (Pbase $=0.016$, Pbase $=0.016$ ), and when comparing 6 months to 9 months $\left(\mathrm{P}=0.025^{*}\right)$.

As for control group, a significant decrease was noted when comparing baseline to 6 and 9 months $\left(\mathrm{P}=0.015^{*}, 0.015^{*}\right)$, and when comparing 6 months to 9 months $\left(\mathrm{P}=0.046^{*}\right)$.

Comparing both groups, a significant reduction was realized in test group after 6 and 9 months(P:0.031*,0.001*) (U:8.000*,0.000*) respectively denoting a reduction in the horizontal component of the furcation (bone fill) in test group by the end of the follow up period (58.4\%)compared to control group (28\%).

Table (1): Comparison between the two studied groups according to horizontal component of the furcation

\begin{tabular}{|c|c|c|c|c|}
\hline $\begin{array}{l}\text { Furcation } \\
\text { horizontal } \\
\text { component }\end{array}$ & Baseline & 6 Months & 9 Months & ${ }^{\mathrm{Fr}} \mathbf{p}$ \\
\hline Test $(n=7)$ & & & & \\
\hline $\begin{array}{l}\text { Min. - } \\
\text { Max. }\end{array}$ & $4.0-5.0$ & $0.0-3.50$ & $0.0-2.50$ & \\
\hline $\begin{array}{r}\text { Mean } \pm \\
\text { SD. }\end{array}$ & $4.64 \pm 0.48$ & $2.64 \pm 1.28$ & $1.93 \pm 0.89$ & $<0.001^{*}$ \\
\hline Median & 5.0 & 3.0 & 2.0 & \\
\hline $\begin{array}{r}\text { Sig. } \\
\text { bet. } \\
\text { Periods } \\
\end{array}$ & \multicolumn{3}{|c|}{$\mathrm{p}_{1}=0.016^{*}, \mathrm{p}_{2}=0.016^{*}, \mathrm{p}_{3}=0.025^{*}$} & \\
\hline $\begin{array}{r}\% \text { of } \\
\text { change }\end{array}$ & & $\downarrow 43.1$ & $\downarrow 58.4$ & \\
\hline $\begin{array}{r}\text { Control } \\
(n=7)\end{array}$ & & & & \\
\hline $\begin{array}{l}\text { Min. - } \\
\text { Max. }\end{array}$ & $4.0-5.0$ & $3.0-4.50$ & & \\
\hline $\begin{array}{r}\text { Mean } \pm \\
\text { SD. }\end{array}$ & $4.57 \pm 0.45$ & $3.86 \pm 0.63$ & $3.29 \pm 0.39$ & $<0.001^{*}$ \\
\hline Median & 4.50 & 4.0 & 3.0 & \\
\hline $\begin{array}{r}\text { Sig. } \\
\text { bet. } \\
\text { Periods }\end{array}$ & \multicolumn{3}{|c|}{$\mathrm{p}_{1}=0.015^{*}, \mathrm{p}_{2}=0.015^{*}, \mathrm{p}_{3}=0.046^{*}$} & \\
\hline $\begin{array}{r}\% \text { of } \\
\text { change }\end{array}$ & & $\downarrow 15.5$ & $\downarrow 28.0$ & \\
\hline $\mathbf{U}$ & 22.0 & $8.000^{*}$ & $0.000^{*}$ & \\
\hline $\mathbf{P}$ & 0.728 & $0.031^{*}$ & $0.001^{*}$ & \\
\hline
\end{tabular}

$\mathrm{U}, \mathrm{p}$ : $\mathrm{U}$ and $\mathrm{p}$ values for Mann Whitney test for comparing between test and control

${ }^{\mathrm{Fr}} \mathrm{p}$ : $\mathrm{p}$ value for Friedman test for comparing between the different periods in each group

Sig between periods was done using Wilcoxon signed ranks test

$\mathrm{p}_{1}$ : $\mathrm{p}$ values for comparing between Baseline and 6 Months $\mathrm{p}_{2}$ : $\mathrm{p}$ values for comparing between Baseline and 9 Months р3: $p$ values for comparing between 6 and 9 Months

*: Statistically significant at $\mathrm{p} \leq 0.05$ 


\section{Vertical component of the furcation (Table 2)}

At baseline, the mean vertical component of the furcation was $(4.29 \pm 0.27 \mathrm{~mm})$ for both test and control groups.

A significant decrease was noted in test group when comparing baseline to 6 and 9 months. (P1 :0.016*, P2: 0.016*). However, this difference was insignificant when comparing 6 months to 9 months. (P3:0.102*).

As for control group, no significant difference was noted neither when comparing baseline to 6 and 9 months (P1:0.063, P2:0.063), nor when comparing between the different follow up periods. (P3:1.000).

Comparing both groups, a significant reduction of the vertical component of the furcation was realized after 6 and 9 months in test group compared to control group. $\left(\mathrm{P}: 0.008^{*}, 0.001^{*}\right)(\mathrm{U}: 4.0 *, 0.000 *)$ respectively indicating an improvement in the vertical component of the furcation (bone fill) in test group by the end of follow up period (63.4\%) compared to control group (23.3\%). (Figure 6)

Table (2): Comparison between the two studied groups according to vertical component of the furcation

\begin{tabular}{|c|c|c|c|c|}
\hline $\begin{array}{l}\text { Furcation } \\
\text { vertical } \\
\text { component }\end{array}$ & Baseline & 6 Months & 9 Months & ${ }^{\mathrm{Fr}} \mathbf{p}$ \\
\hline Test $(n=7)$ & & & & \\
\hline Min. - Max. & $4.0-4.50$ & $0.0-3.0$ & $0.0-2.0$ & \\
\hline Mean \pm SD. & $4.29 \pm 0.27$ & $1.86 \pm 0.94$ & $1.57 \pm 0.79$ & $0.002^{*}$ \\
\hline Median & 4.50 & 2.0 & 2.0 & \\
\hline $\begin{array}{l}\text { Sig. bet. } \\
\text { Periods }\end{array}$ & \multicolumn{3}{|c|}{$\mathrm{p}_{1}=0.016^{*}, \mathrm{p}_{2}=0.016^{*}, \mathrm{p}_{3}=0.102$} & \\
\hline$\%$ of change & & $\downarrow 56.6$ & $\downarrow 63.4$ & \\
\hline Control $(n=7)$ & & & & \\
\hline Min. - Max. & $4.0-4.50$ & $2.50-4.0$ & $2.50-4.0$ & \\
\hline Mean \pm SD. & $4.29 \pm 0.27$ & $3.29 \pm 0.70$ & $3.29 \pm 0.70$ & $0.018^{*}$ \\
\hline Median & 4.50 & 3.0 & 3.0 & \\
\hline $\begin{array}{l}\text { Sig. bet. } \\
\text { Periods }\end{array}$ & \multicolumn{3}{|c|}{$\mathrm{p}_{1}=0.063, \mathrm{p}_{2}=0.063, \mathrm{p}_{3}=1.000$} & \\
\hline$\%$ of change & & $\downarrow 23.3$ & $\downarrow 23.3$ & \\
\hline $\mathbf{U}$ & 24.50 & $4.0^{*}$ & $0.000^{*}$ & \\
\hline $\mathbf{P}$ & 1.000 & $0.008^{*}$ & $0.001^{*}$ & \\
\hline
\end{tabular}

$\mathrm{U}, \mathrm{p}$ : $\mathrm{U}$ and $\mathrm{p}$ values for Mann Whitney test for comparing between test and control

${ }^{\mathrm{Fr}} \mathrm{p}$ : $\mathrm{p}$ value for Friedman test for comparing between the different periods in each group

Sig. between periods was done using Wilcoxon signed ranks test

$\mathrm{p}_{1}$ : $\mathrm{p}$ values for comparing between Baseline and 6 Months $\mathrm{p}_{2}$ : $\mathrm{p}$ values for comparing between Baseline and 9 Months p3: $\mathrm{p}$ values for comparing between 6 and 9 Months

\section{DISCUSSION}

The present study was carried out to evaluate clinically and radiographically the use of ACM augmented with beta tricalcium phosphate and hydroxy apatite bone graft (biphasic alloplast) in the management of grade II furcation defects. The study comprised two groups: Group I (Test group): In which seven furcation defects were augmented with bone graft covered by ACM, and group II
(Control group): In which seven furcation defects were augmented with bone graft covered by a resorbable collagen membrane.

In the current study the patients were selected free from any systemic diseases or a condition that may complicate the surgical procedure or interfere with the healing process of furcation defects for e.g: diabetes mellitus can affect bone regeneration as hyperglycemia affects metabolism of phosphorus and calcium which are essential for bone mineralization and remodeling. In addition, diabetes mellitus inhibits osteoblastic differentiation, impairs circulation, reduces chemotaxis and phagocytosis of neutrophils thus increases the susceptibility for infection (23).

All patients in the current study were non-smokers as nicotine, which is the major component of tobacco, is cytotoxic and prevents the differentiation of osteoblast-like cells to osteoblasts thus interfering with healing and bone regeneration. Also, the local absorption of nicotine into blood stream causes vasoconstriction which is a detrimental factor in healing and regeneration (24).

Moreover all the selected cases had no para functional habits such as bruxism and clenching, which increase the magnitude of the forces and may lead to bone resorption and impaired regeneration (25).

In the present study probing depth, and clinical attachment loss were evaluated along the follow up period. As those clinical parameters and their results indicate the progress of healing and regeneration (26).

In the present study panoramic radiographs were used in patient selection, while CBCT was used to evaluate the vertical and horizontal components of the furcation. The latter has the advantage of enabling an exact estimation and classification of furcation involvement, as well as visualization of root morphologies, and observation of periodontal defects in all directions (27). CBCT images are free of magnification, superimposition of neighboring structures, and other problems inherent to panoramic radiology (28).

Clinical results of the current study revealed that ACM membrane exhibits easy handling during manipulation compared to collagen membrane, which may be due to its standardized shape, size, and thickness. Therefore, it does not require trimming compared to collagen membrane (29).

When compared to collagen membranes, ACM are easier to apply due to the self adhering properties of the membrane, so it does not require sutures for fixation.This property may be due to the presence of adherent molecules as laminin and fibronectin(30). The ease of application of ACM is due to its thickness of about 300 micrometer, compared to traditional collagen membranes' thickness of 700-800 micrometers. This property together with the self adhering property of ACM allow it to ultimately mold to the defect anatomy and adapt to the contours around the roots' surfaces. All the previous properties of ACM facilitate its use, and save time (30).

Regarding PD and CAL in the current study, there is reduction in them in test group compared to control group throughout the follow up period. This reduction may be due to the antibacterial and the anti-inflammatory properties of ACM, which may decrease the influx of inflammatory cells and inflammatory mediators to the wound area and serve as a barrier (31), also it was found 
that ACM releases inhibitors of matrix metalloproteinases, e.g: 1, 2, 3, and 4, which are released by infiltrating neutrophils and macrophages (32).

Moreover, the matrix of amniotic membrane stroma has the ability to suppress pro-inflammatory mediators e.g: interleukin- $\alpha$ and interleukin-1 $\beta$ (33). ACM also reinforces basal cell adhesion, due to the significant amounts of laminin and laminin-5 (34).

Additionally, chorion matrix contains abundant growth factors, such as keratinocyte growth factor, basic fibroblast growth factor, and transforming growth factor $\beta$, that promote periodontal regeneration (16), and provide a natural environment for accelerated healing (35).

The results of the current study are consistent with those of another one that showed a reduction in PD and CAL after 6 months follow up period ,the later study used a composite allograft containing mesenchymal cells with ACM to treat mandibular class III furcation defects.(36)Furthermore, a retrospective study by Holtzclaw (35), revealed that localized moderate-to-severe chronic periodontitis patients treated by ACM combination-GTR therapy, had an average PD reduction and CAL improvement after 12 months follow up period. He concluded that ACM may hold promise for regeneration and treating the most challenging clinical dilemmas.

Radiographic results from the current study have shown a significant decrease of the vertical and horizontal furcation components (gain in the bone fill) in test group after six, and nine months when compared to control group. These results are consistent with those of the study using composite allograft containing mesenchymal cells with ACM to treat a mandibular class III furcation, in which three-dimensional imaging at 6 months using CBCT suggested complete furcation closure (35).

Also, the current study is in agreement with Kumar et al. (37) who used amniotic membrane with hydroxyapatite bone graft to manage contained interdental defects. A significant gain in bone fill was observed at test group from baseline to 24 weeks. They concluded that amniotic membrane has the potential to function as a barrier for GTR and can act as a matrix for periodontal regeneration as well. Similarly, Kothiwale et al (38) evaluated the efficacy of demineralized freeze-dried bone allograft and bovine derived xenogeneic bone graft with amniotic membrane in the treatment of Grade II buccal furcation defects. Results showed significant pocket depth reductions, clinical attachment level gains, and significant improvement in bone fill.

The improvement of the horizontal and vertical furcation components be due to the bone inductive potential of ACM which is due to the ability of the membrane to up-regulate the recruitment of mesenchymal progenitor cells which demonstrate osteogenic and adipogenic differentiation (39). At the same time, ACM shows excellent acceptability with bone grafts by demonstrating excellent containment of the material and its resorption without the formation of voids (40). When compared to collagen membrane, ACM also demonstrated many unique properties such as that it possesses a variety of proteins that provide a bioactive matrix to facilitate wound healing (30).
ACM encourages rapid epithelial cell growth rather than epithelial exclusion which is a different manner of action from traditional (GTR) barriers, in other words the presence of the laminin proteins cause the rapid epithelial growth along the membrane, so the new junctional epithelium forms faster which allows for epithelial exclusion from the bone defect (29). So ACM is believed to be beneficial in periodontal regeneration as it contains abundant growth factors, and it up regulates stem cell recruitment allowing for these cells along with the soluble bioactive proteins in the membrane to enter into the wound space, thereby accelerating healing, decreasing inflammation and then allowing for the periosteum to participate in bone healing (13).

\section{CONCLUSION}

Amnion chorion membrane is an effective, easy to handle, safe, and time saving membrane that can be used for periodontal regeneration.

\section{CONFLICT OF INTEREST}

The authors report no conflict of interest relevant to this article.

\section{REFERENCES}

1. Newmann MG, Takei HH, Carranza FA. Carranza's clinical periodontology.9th ed. Philadelphia: WB Saunders Co, 2002. P 67.

2. Sims T, Takei HH. Furcation involvement and treatment. In: Newman MG, Takei HH. Klokkevold PR, Carranza FA (eds). Caranza's Clinical Periodontology. 12th ed. Philadelphia: Elsevier Saunders; p 621-7.

3. American Academy of Periodontology. Parameter on occlusal traumatism in patients with chronic periodontitis. J Periodontol. 2000:71(Suppl5): 873-5.

4. Shenoy VK, Rodrigues S. latrogenic dentistry and the periodontium. J Indian Prosthodont Soc. 2007;7:17-20

5. Graetz C, Plaumann A, Wiebe JF, Springer C, Salzers, Dorfer CE. Periodontal probing versus radiographs for diagnosis of furcation involvement. J Periodontol 2014;85:1371-9.

6. Pradeep AR, Priyanka N, Kalra N, Naik SB, Singh SP, Martande S. Clinical efficacy of subgingivally delivered $1.2 \mathrm{mg}$ simvastatin in the treatment of individuals with Class II furcation defects: a randomized controlled clinical trial. J Periodontol. 2012; 83:1472-3.

7. Jepsen S, Eberhard J, Hernera D, Needlenem T. A systematic review of guided tissue regeneration for periodontal furcation defects. What is the effect of guided tissue regeneration compared with surgical debridement in the treatment of furcation defects? J Clin Periodontol. 2002; 29(Suppl3):103-16, 160-2.

8. Gamal AY, lacono VJ. Enhancing guided tissue regeneration of periodontal defects by using a novel perforated barrier membrane. J Periodontol. 2013;84:90513.

9. Wang HL, Cooke J. Periodontal regeneration techniques for treatment of periodontal diseases.Dent Clin North Am. 2005;49:637-59.

10. Santan RB, Leite de Mattos GM, Dyke TV. Efficacy of combined regenerative treatments in human mandibular class II furcation defects. J Periodontol. 2009;80:1756-64.

11. Gianobelle WV, Rayan S, Shih MS, Su DL, Kaplan PL, Chan TCK. Recombinant human osteogenic protein-1(OP- 
1) stimulates periodontal wound healing in class III furcation defects. J Periodontol. 1998;69:129-37.

12. Rosen P. A Case Report on Combination Therapy Using a Composite Allograft Containing Mesenchymal Cells With an Amnion-Chorion Barrier to Treat a Mandibular Class III Furcation. Clinical Advances in Periodontics 2013;2:64-69.

13. Gupta A, Kedige S, Jain k. Amnion and chorion membranes: potential stem cell reservoir with wide applications in periodontics. Int J Biomater 2015;2015:1-9.

14. Pakkala T, Virtanen I, Oksanen J, Jones C, Hormia M. Function of laminins and laminin binding integrins in gingival epithelial cell adhesion. $\mathrm{J}$ Periodontol. 2002;73:709-19.

15. Glickman I. Clinical Periodontology 4th ed. Philadelphia: WB Saunders Co; 1964. p 203-5.

16. Daniel W. Biostatistics. A foundation for analysis in the health science .6th ed. NY: John Wiley and sons, Inc; 1995.

17. Paul S, Stuart J, Cohen D. Consecutive case series using a composite allograft containing mesenchymal cells with an amnion chorion barriers to treat mandibular class III/IV furcations. IJPR 2015;35:453-60.

18. Tarnow D, Flecher P. Classification of vertical component of furcation involvement. J Periodontol. 1984; 55:283-4.

19. Glavind L, Loe H. Error in the clinical assessment of periodontal destruction. J Periodont Res. 1967;2:180

20. Ramachandran GN, Lakshminarayanan AV. Three dimensional reconstruction from radiographs and electron micrographs: Application convolutions instead of Fourier Transforms. Proc Natl Acad Sci USA. 1971;68:2236-40.

21. Kotz S, Balakrishnan N, Read CB, Vidakovic B. Encyclopedia of statistical sciences. 2nd ed. Hoboken, NJ: Wiley-Interscience; 2006.

22. Kirkpatrick LA, Feeney BC. A simple guide to IBM SPSS statistics for version 20.0. Student ed. Belmont, Calif: Wadsworth, Cengage Learning; 2013.

23. Leonhardt A, Dahlen G, Envert S. Five-year clinical, microbiological and radiological outcome following treatment of peri-implantitis in man. J Periodontol. 2003;74:1415-22.

24. Patel RA, Wilson RF, Palmer RM. The Effect of Smoking on Periodontal Bone Regeneration: A Systematic Review and Meta-Analysis. J Periodontol. 2012;83:143-55.

25. Manfredini D, Poggio CE, Lobbezoo F. Is bruxism a risk factor for dental implants? A systemic review of the literature. Clin Implant Dent Relat Res. 2012;16:460-9.

26. Dastoor SF, Travan S, Wang HL. Effect of Adjunctive Systemic Azithromycin With Periodontal Surgery in the Treatment of Chronic Periodontitis in Smokers: A Pilot Study. J Periodontol. 2007;78:1887-96.

27. Misch KA, Yi ES, Sarment DP. Accuracy of Cone Beam Computed Tomography for Periodontal Defect Measurements. J Periodontol 2006;77:1261-66.

28. Angelopoulos C, Thomas S, Hechler S, Parisis N, Hlavacek M. Comparison Between Digital Panoramic Radiography and Cone-Beam Computed Tomography for the Identification of the Mandibular Canal as Part of Presurgical Dental Implant Assessment. J Oral Maxillofac Surg. 2008;66:2130-5.

29. Holtzclaw D, Toscano N. Amnion chorion allograft barrier: Indications and techniques update. JIACD. 2012;4:25-38
30. Koizumi NJ, Inatomi TJ, Sotozono CJ, Fullwood NJ, Quantock AJ, Kinoshita S. Growthfactor m RNA and protein in preserved human amniotic membrane. Curr Eye Res. 2000;20:173-7.

31. Shimmura S, Shimazaki J, Ohashi Y, Tsubota K. Antiinflammatory effects of amniotic membrane transplantation in ocular surface disorders. Cornea. 2001;20:408-13.

32. Gupta I, Gupta R, Gokhale ST, Sharma A. Placental tissues: fixing smiles. Int J Innov Scientific Res 2014;7:5762.

33. Sali DD, George JP. Demineralized Freeze Dried Bone Allograft With Amniotic Membrane in the Treatment of Periodontal Intrabony Defects - 12 Month Randomized Controlled Clinical Trial. J Periodontol. 2016;10:1-18.

34. Holtzclaw D, Hinze HF, Toscano N. Gingival flap attachment healing with amnionchorion allograft membrane: A controlled, split mouth case report replication of the classic 1968 Hiatt Study. J Implant Adv Clin Dent 2012;4:19-25.

35. Holtzclaw DJ, Toscano NJ. Amnion-chorion allograft barrier used for guided tissue regeneration treatment of periodontal intrabony defects: A retrospective observational report. Clin Adv Periodontics 2013;3:131-7.

36. Rosen PS. A Case Report on Combination Therapy Using a Composite Allograft Containing Mesenchymal Cells With an Amnion-Chorion Barrier to Treat a Mandibular Class III Furcation. Clin Adv Periodontics. 2013;3:64-69.

37. Kumar A, Chandra RV, Reddy AA, Reddy BH, Reddy C, Naveen A. Evaluation of clinical, antiinflammatory and antiinfective properties of amniotic membrane used for guided tissue regeneration: A randomized controlled trial. Dent Res J (Isfahan). 2015; 12:127-35.

38. Kothiwale SV, Anuroopa P, Gajiwala AL. A clinical and radiological evaluation of DFDBA with amniotic membrane versus bovine derived xenograft with amniotic membrane in human periodontal grade II furcation defects. Cell Tissue Bank 2009;10:317-26.

39. In 't Anker PS, Scherjon SA, Kleijburg-van der Keur C, de Groot-Swings GM, Claas FH, Fibbe WE, et al. Isolation of mesenchymal stem cells of fetal or maternal origin from human placenta. Stem Cells. 2004;22:1338-45.

40. Gomes JA, Romano A, Santos MS, Dua HS. Amniotic membrane use in ophthalmology. Curr Opin Ophthalmol. 2005;16:233-40. 